\title{
Scaling-Up of an Up-Flow Anaerobic Sludge Blanket Incorporated With a Bio-Filter Liner System for Treating Kitchen Wastes
}

\author{
R.T.K. Ariyawansha*, B.F.A. Basnayake ${ }^{1}$ and A.K. Karunarathna ${ }^{1}$ \\ Postgraduate Institute of Agriculture \\ University of Peradeniya \\ Peradeniya
}

\begin{abstract}
A bottom biofilter liner incorporated to an Up-flow Anaerobic Sludge Blanket Reactor (UASBR) was designed, developed and evaluated for food wastes for 47 days as a semi-batch set-up with intermittent up-flow circulation (very infrequent) to simulate the start-up. This study was conducted to scale-up already developed UASBR. In the mineralization process, the surface area at the bottom of the reactor is the most critical parameter. Thus, it has been found that total dissolved solids (TDS) of bottom, middle and top strata seem to follow first order rate reactions. The TDS was divided by the feeding that took place at different times to give a unit production of TDS at timet. The average unit value of the bottom strata was then divided by the lowest experimental TDS value, thus yielding a ratio equating the two areas of desired to that of the experimental value. Therefore, a diameter (or area) could be found for any loading rate. The height of the reactor was found by considering ratios of the volumes to that of the predicted maximum TDS concentration obtained from the learning curve of the first order reactions and the maximum experimental value. The total height of reactor is $3.4 \mathrm{~m}$, which is optimum for kitchen wastes, would remain constant for different loading rates. A prototype would be constructed and performance would be evaluated to reconfirm the hypothesis that a biofilter liner system is effective in reducing inhibitions often encountered in UASB reactors
\end{abstract}

Keywords: Biofilter liner, first order equation, upflow anaerobic sludge blanket reactor, scaling-up

\section{INTRODUCTION}

Food waste generated from homes, restaurants, and catering facilities, food markets, and food processing activities constitutes one of the largest components of the waste streams around the world (Nagao et al., 2012) including Sri Lanka. This is due to improper management, as well as inadequate harvest techniques, poor post-harvest management, lack of suitable infrastructure, processing, packaging, and low-quality marketing information and also due to the inadequate awareness of food waste management and environmental protection education (Dung et al., 2014). Consequently, food waste constitutes a source of nuisance in municipal landfills because of their high biodegradability (Misi et al., 2002; Bouallagui et al., 2005; Dung et al., 2014). Food waste has the potential to be a valuable resource if disposed of correctly; meaning that treatment technology and the utilization of the recycled products based on sustainable criteria are important (Wen et al., 2016).

\footnotetext{
1 Department of Agricultural Engineering, Faculty of Agriculture, University of Peradeniya, Sri Lanka

* Corresponding author: chathunisha@gmail.com
} 
There are various methods available for the treatment of food waste. Nevertheless, anaerobic processes are widely used (Annachhatre, 1996) because it appears to be a suitable and sustainable technology (Mata-Alvarez et al., 1992; Bouallagui et al., 2005; Mahmoud et al., 2004). The several favorable characteristics of anaerobic processes, such as low cost, operational simplicity, low biosolids production and considerable biogas production (Chen et al., 2011). The biogas can be used to produce green electricity, heat or as engine fuel (Bouallagui et al., 2005; Jha et al., 2013) and the slurry or digestate which eventually can be used as organic fertilizer or an excellent soil conditioner after minor treatments (Bouallagui et al., 2005; Nagao et al., 2012; Jha et al., 2013). As modern anaerobic processes used for high rate reactors, the up-flow anaerobic sludge blanket reactor (UASBR) is widely used in industrial and domestic waste treatment around the world (Oktem et al., 2008; Chen et al., 2008). This is mainly due to its simple design, easy construction and maintenance, low operating cost, ability to withstand fluctuations in $\mathrm{pH}$, temperature and influent substrate concentration (Chen et al., 2011). A satisfactory operation of an anaerobic treatment facility requires proper control of the system, as far as possible and economical, and the maintenance of optimal environmental conditions (Lettinga and Pol, 1991).

UASBR processes are based on the development of dense granules $(1-4 \mathrm{~mm})$ in the reactor (Nicolella et al., 2000). The perceived problem of long start-up periods for the UASBRs is due to the time required for the anaerobic granulation (McHugh et al., 2003). Further, lipids degradation is seen as a rate limiting step for food waste anaerobic digestion. High concentration of lipid can cause process instability through sludge flocculation (biomass wash out), direct inhibition, VFAs overload (Awe et al., 2017). According to Awe et al., 2017 lipids inhibitions could be addressed with the combination of $\mathrm{NaOH}$ addition coupled with recirculation of certain percentage of the digester's effluent. According to Habeed et al., 2011, the overload of minerals existing in UASBRs have absolutely led to process inhibition, and also caused ash (Total fixed Solids (TFS)) formations instead of activated granules. Therefore, a pilot/ laboratory scale UASBR was designed, developed, and evaluated for food wastes for 47 days. It was operated as a semi-batch setup to simulate the start-up process (Karunarathne et al., 2017). A key feature of the developed UASBR is incorporation of the clay-polyethylene-clay composite liner system developed by University of Peradeniya which is a live biofilter as a bottom liner of the reactor to make anaerobic system biologically stable, providing optimum conditions for anaerobic digestion via reducing the inhibitions (Gunarathne et al., 2010; Thivyatharsan et al., 2012). The importance of vertical movement through dissimilar surfaces provides ideal conditions for both mineralization and conversion of ammonia to nitrate. The mineralized compounds are formed within the narrow passages and above the liner as solid phase reactions (Gunarathne et al., 2010; Thivyatharsan et al., 2012). As reported by Karunarathne et al., 2017, the combined effect of phosphate, initial recirculation and the liner system that made the reactor to perform in an efficient manner through providing a vertical downward movement of excess ions while biogas was moving upwards. Small-scale experiments based on the result of such analysis or on the results of a dimensional analysis can give valuable information for scale-up or optimization fermentation processes (Sweere et al., 1987). Melidis et al., 2003 advise that severe scale-up effects are avoided if the full scale reactor height, identical gas velocities and the same ratio of cross sectional area/volume are applied at pilot scale. Therefore, this study was conducted to develop a procedure to scale up the developed UASBR. 


\section{MATERIALS AND METHODS}

\section{Laboratory Scale/Pilot Scale Experiment}

The main components of the experimental UASBR were, namely; a feeding cup, a gas collecting system, clay-waste polyethylene-clay composite liner, a liquid level indicator, a liquid recirculation system, an outlet and sampling ports as shown in Figure 1. The permeability of the liner system attained a value of $4.713 \times 10^{-6} \mathrm{~cm} / \mathrm{s}$ (Karuanrathne et al., 2017). Initially, $4.2 \mathrm{~kg}$ of shredded food waste and $12.5 \mathrm{~L}$ of water was added. After that, 1.1 $\mathrm{kg}$ of partially degraded waste from a hydrolytic reactor was fed after 20 days, 39 days and 43 days of operation. After 7 days of operation, $500 \mathrm{~mL}$ of $2 \mathrm{M}$ potassium phosphate solution was added. One litter of $5.35 \mathrm{M}, 1.8 \mathrm{M}$ and $1.8 \mathrm{M} \mathrm{Ca}(\mathrm{OH})_{2}$ solution was fed after 11 days, 22 days and 39 days of operation respectively. After 29 days of operation, $300 \mathrm{~g}$ of fresh cow dung mixed with $1.5 \mathrm{~L}$ of water was fed. For first 18 days of the operating period, leachate recirculation was done for 15 minutes/day. For next 19 days, recirculation was performed for 15 minutes at 3 hour intervals continuously. After that, the recirculation was stopped (Karunarathne et al., 2017).

\section{Scaling-up of the reactor}

The initial concentration of the kitchen wastes was $75.6 \mathrm{~g} / \mathrm{L}$ occupying a volume of 19.44 liters deduced from the feeding rate of $4.2 \mathrm{~kg}$ at moisture content of $65 \%$. Subsequently on three occasions, $1.1 \mathrm{~kg}$, having a total solid concentration of $19.8 \mathrm{~g} / \mathrm{L}$ each was fed after the start-up to maintain gas generations and general activities of anaerobic digestion.

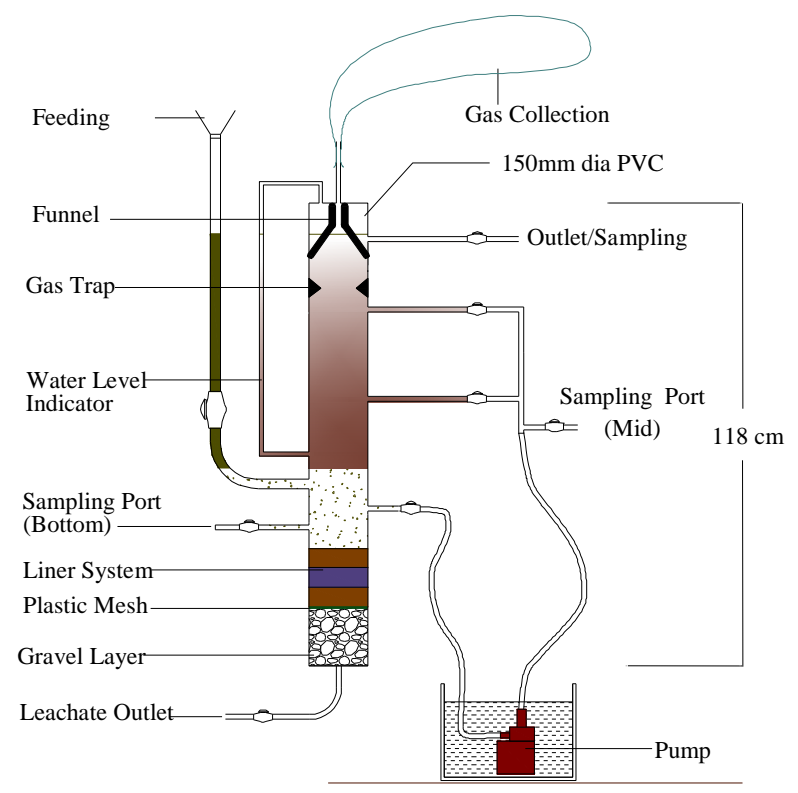

Figure 1. Schematic diagram of the laboratory scale experimental setup of the UASBR (Karunarathne et al., 2017) 


\section{Analyses \\ First order reactions}

The first order rate reactions are not clearly defined in most of the literature because of the confusion arising in the integral forms of the reactions. Let us examine the mathematical relationship in terms of concentration $[c]$. Such that;

$\frac{d c}{d t}=-k[c]$

In order to determine $c$ in terms of time $t$, the integral can be written as;

$\int_{C_{o}}^{c_{t}} \frac{d c}{[c]}=-k \int_{0}^{t} d t$

$c_{t}=C_{o} e^{-k t}$

Where, $c_{t}=$ concentration at time $t, C_{o}=$ initial concentration, $k=$ rate constant, and $t=$ time

By substituting eq. (2) in eq. (1) for $c$, the eq. (1) can then be rewritten in terms of time t.

$\frac{d c}{d t}=-k C_{o} e^{-k t}$

The integral of the above equation (1a) validates equation (2), thus; $c_{t}=C_{o} e^{-k t}$

The sum total of $c_{t}$, the cumulative value $c_{c}$ can be obtained from the learning curve, where;

$c_{c}=\int_{0}^{t} d\left(c_{t}\right)=\int_{0}^{t} C_{o} e^{-k t} \times d t=\left[-\frac{C_{o}}{k} e^{-k t}\right]_{0}^{t}=C_{u l t}\left(1-e^{-k t}\right)$

Where, $C_{u l t}=$ ultimate concentration. Another learning curve is obtained if the products of the reactions, $c_{p}$ are considered where; $c_{p}=C_{o}-c_{t}=C_{o}-C_{o} e^{-k t}=C_{o}\left(1-e^{-k t}\right)$

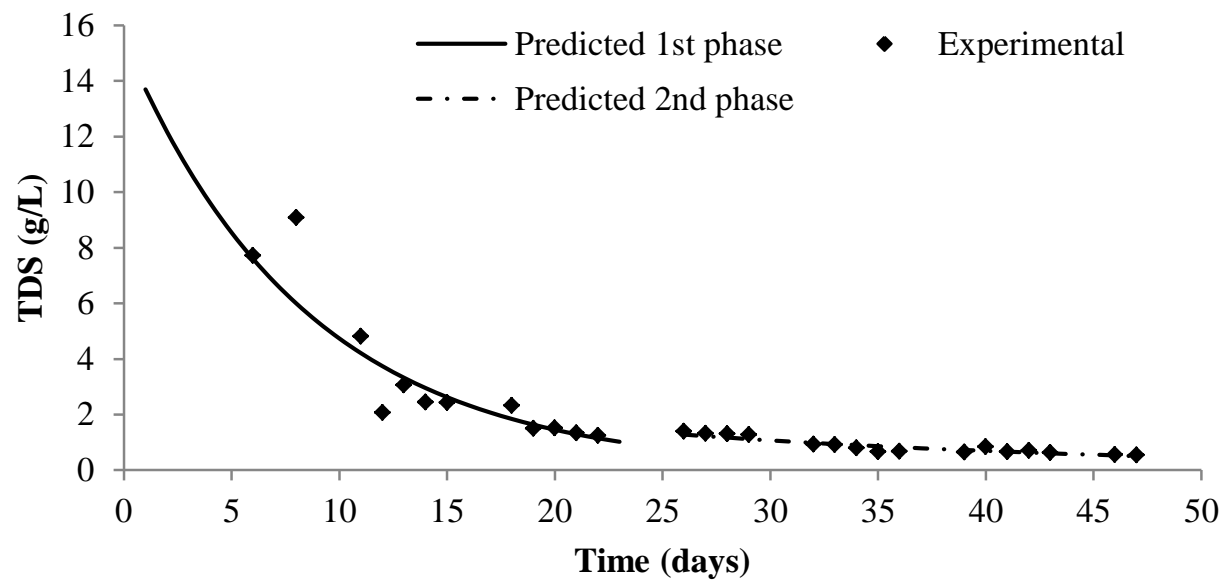

Figure 2. TDS concentration of the bottom stratum variations with time 


\section{Total dissolved solids (TDS)}

It has been found that unlike all of the other parameters, TDS seems to follow first order rate reactions. They were expressed as eq. $2 \mathrm{a}$ and eq. $2 \mathrm{~b}$ of the two phases as shown in Figure 2. The reactions of the second phase were due to feeding that perhaps caused granular formations (Thaveesri et al., 1995; Pol et al., 2004; Zhou et al., 2007).

$$
\begin{aligned}
& T D S_{t}=T D S_{o 1} e^{-k_{1} t} \\
& T D S_{t}=T D S_{o 2} e^{-k_{2} t}
\end{aligned}
$$

and

Where; $T D S_{t}=T D S$ concentration at time $t, k_{1}$ and $k_{2}=$ rate constant of the first phase and the second phase, $T D S_{o 1}$ and $T D S_{o 2}=$ initial concentration of the first phase and the second phase. The initial concentrations for each phase were obtained from the intercept of the linear regression of experimental $\ln (T D S)$ of each phase vs time $t$. Therefore, eq. 1 can be rewritten for each of the phases in the form of;

$$
\begin{aligned}
& \frac{d(T D S)}{d t}=-k_{1} T D S_{o 1} e^{-k_{1} t} \\
& \frac{d(T D S)}{d t}=-k_{2} T D S_{o 2} e^{-k_{2} t}
\end{aligned}
$$

Where, $T D S_{o 1}$ and $T D S_{o 2}$ are initial values of the first and second phase reactions. In the mineralization process, the surface area at the bottom of the reactor is the critical parameter. The surface area of the scaled up reactor should then be in proportion to the existing area based on the predicted scaled up reactor concentrations to that of the experimental concentrations.

$$
\frac{\text { Average Scaled }- \text { up Concentration }\left(S C_{a}\right)}{\text { Area of the Scaled - up reactor }}=\frac{\text { Lowest predicted Experimental Concentration }\left(E C_{L}\right)}{\text { Area of the Experimental reactor }}
$$

Area of the scaled - up reactor $=\frac{\pi D^{2}}{4}$

Area of the Experimental reactor $=\frac{\pi d^{2}}{4}$

This ratio can be written as, $D^{2}=\frac{S C_{a} \times d^{2}}{E C_{L}}$

Where, $d$ is the diameter of the experimental reactor and $\mathrm{D}$ is the desired value of diameter of scaled up reactor. Scaled up reactor should neither be the lowest nor the highest concentrations, but an average value could be the best. Although, $T D S_{o}$ written as $T D S_{o 1}$ and $T D S_{o 2}$ are theoretical values, they could have been converted from the initial feeding of 4.2 $\mathrm{kg}$, corresponding to $\mathrm{TS}_{\mathrm{i}}$ such that $T S_{1}=75.6 \mathrm{~g} / \mathrm{L}$ and from subsequent feeding of $T S_{2}=19.8$ $\mathrm{g} / \mathrm{L}$ on $20^{\text {th }}, 39^{\text {th }}$, and $43^{\text {rd }}$ day of operation, thus for a unit production at time $t, \alpha_{t}$ could be deduced as; $\alpha_{t}=\frac{T D S}{T S} e^{-k t}$ 
Hence, for the phase 1 (for the first 25 days), $\alpha_{t}=\frac{T D S_{1}}{T S_{1}} e^{-k_{1} t}$

$(6 a)$,

for the phase 2 (for $26^{\text {th }}$ to $38^{\text {th }}$ day) $\alpha_{t}=\frac{T D S_{2}}{T S_{1}+T S_{2}} e^{-k_{2} t}$

$(6 b)$,

for the phase 2 (for $39^{\text {th }}$ to $42^{\text {nd }}$ day) $\alpha_{t}=\frac{T D S_{2}}{T S_{1}+2 T S_{2}} e^{-k_{2} t}$

$(6 c)$,

and for the phase 2 (for $43^{\text {rd }}$ to $47^{\text {th }}$ day) $\alpha_{t}=\frac{T D S_{2}}{T S_{1}+3 T S_{2}} e^{-k_{2} t}$

Hence, $D=\sqrt{\frac{\alpha_{a} \times T S_{i} \times d^{2}}{T D S_{t=47}}}$

Where, $d$ is the diameter of the experimental reactor and $\alpha_{a}=$ average unit value derived from phase 1 and 2 of TDS to TS that were fed to the reactor for 47 days. The TDS concentration at the end of 47 days was very low, thus ensures a larger diameter for a scaledup reactor at high loading rates. Organic loading rate can be considered as the most critical factor that should be carefully adjusted (Habeeb et al., 2011). In fact, the variation of D as a function of input concentration/loading rate $\left(\mathrm{TS}_{\mathrm{i}}\right)$ can be plotted. Once the diameter or the area is known, the variation in the height of the reactor can be deduced. As stated before, 4.2 $\mathrm{kg}$ of wastes were used for the start-up, which led to the first phase reactions. As before, let us assume that $4.2 \mathrm{~kg}$ is fed daily, then;

$$
\begin{aligned}
& T D S_{c 1}=T D S_{u l t 01}\left(1-e^{-k_{1} t}\right) \\
& T D S_{c 2}=T D S_{u l t o 2}\left(1-e^{-k_{2}(t-22)}\right)
\end{aligned}
$$

Where, $T D S_{c 1}$ and $T D S_{c 2}=$ cumulative concentration of $T D S$ in the first phase reactions and the second phase reactions, $T D S_{\text {ultol }}$ and $T D S_{\text {ulto2 }}=$ Ultimate $T D S$ concentration of the first phase and second phase respectively. In order to scale-up the reactor, it is necessary to express in terms of a unit $(1 \mathrm{~kg})$. Then the predicted cumulative values have to be divided by $75.61 \mathrm{~g} / \mathrm{L}(4.2 \mathrm{~kg})$. It is essential to assume a design criterion to equate the concentrations of cumulative $T D S_{c 1}$ from eq. ( $\left.3 \mathrm{a}\right)$ on the $22^{\text {nd }}$ day plus $T D S_{c 2}$ at time $t=47$ days of the scaledup unit reactor to that of the predicted saturated experimental value of $T D S_{o 1}$ from eq. (2a) in relations to the volumes occupied. Where;

$$
\begin{aligned}
& \frac{A_{u} \times H}{A_{e} \times h}=\frac{T D S_{c 1 \& c 2}}{T D S_{o 1}} \\
& \frac{T D S_{c 1 \& c 2}}{A_{u} \times H}=\frac{T D S_{o 1}}{A_{e} \times h} \\
& H=\frac{T D S_{c 1 \& c 2} \times d^{2} \times h}{T D S_{o 1} \times D^{2}}
\end{aligned}
$$

Where; $A_{e}=$ area of the base of the experimental reactor $=\pi d^{2} / 4, A_{u}=$ area of the base of the scaled-up reactor $=\pi D^{2} / 4, T D S_{c 1 \& c 2}=$ highest concentration at time $t=47$ days, 
$T D S_{o 1}=$ predicted experimental maximum TDS value as given in eq.(2a), $\mathrm{h}=$ height of the layer in meters and it is proportionate to the concentrations of each layer with respect to the total height of the experimental reactor and $\mathrm{H}=$ scaled-up height of the reactor. It should be noted that $T D S_{c 2}$ is only applicable for bottom layer.

\section{RESULTS AND DISCUSSION}

An anaerobic process involves the degradation of complex high molecular weight organic compounds to predominantly methane and carbon dioxide. The process can be divided into four phases: hydrolysis, acidogenesis, acetogenesis/dehydrogenation, and methanation. The formation of TDS is an important step in anaerobic digestion since the TDS becomes the substrate for the acetogenic and methanogenic microorganisms. Hydrolysis and acidogenic reactions form hydrogen or formate, carbon dioxide, pyruvate, volatile fatty acids and other organic products such as ethanol, ketones or lactic acid (Mata-Alvarez, 2004), which become a substrate for subsequent conversions for acetogenic and methanogenic bacteria to produce $\mathrm{CH}_{4}$ and $\mathrm{CO}_{2}$. Considerable amounts of $\mathrm{CO}_{2}$ and $\mathrm{H}_{2}$ are formed in the hydrolysis and acidogenic reactions. The later gets converted to acids depending on the partial pressures. There are also pathways to convert $\mathrm{CO}_{2}$ and $\mathrm{H}_{2}$ directly to $\mathrm{CH}_{4}$ and $\mathrm{CO}_{2}$. There are many fluctuations between solid, liquid, and gas phase reactions, thus mass balancing is difficult. Carbon dioxide provides oxygen and energy for acitoclastic methanogenic bacteria for these transformation processes. Although TDS has not been extensively used in determining kinetic parameters of anaerobic reactions, it has become an important result in the laboratory scale UASB reactor. Because it shows a first order rate reactions taking place in comparison to other parameters such as total solids (TS), volatile solids (VS), total suspended solids (TSS), volatile suspended solids (VSS), and $\mathrm{pH}$ that indicate randomness due to interventions, feeding and particularly changes in physical state. Also salinity and conductivity as indicative parameters of TDS follow first order kinetics. The kinetic parameters show a very close relationship of first order rate constant $k$ of salinity and conductivity (Table 1).

Table 1. Kinetic parameters

\begin{tabular}{|c|c|c|c|c|c|c|}
\hline \multirow{2}{*}{\multicolumn{2}{|c|}{ Parameter }} & \multicolumn{2}{|c|}{$k\left(\right.$ day $\left.^{-1}\right)$} & \multicolumn{3}{|c|}{$C_{o}$} \\
\hline & & \multirow{2}{*}{$\begin{array}{l}k_{1} \\
-0.118\end{array}$} & \multirow{2}{*}{$\begin{array}{l}k_{2} \\
-0.044\end{array}$} & \multirow{2}{*}{$\begin{array}{l}C_{o 1} \\
15.410\end{array}$} & \multirow{2}{*}{$\begin{array}{l}C_{o 2} \\
4.015\end{array}$} & \multirow{2}{*}{$\begin{array}{r}\text { unit } \\
g / L\end{array}$} \\
\hline & Bottom & & & & & \\
\hline & Mid & -0.038 & & 3.360 & & $\mathrm{~g} / \mathrm{L}$ \\
\hline \multirow[t]{3}{*}{ TDS } & Top & -0.040 & & 3.673 & & $\mathrm{~g} / \mathrm{L}$ \\
\hline & Bottom & -0.11 & -0.0425 & 26.115 & 7.792 & $\mathrm{mS}$ \\
\hline & Mid & -0.0342 & & 6.167 & & $\mathrm{mS}$ \\
\hline \multirow[t]{3}{*}{ Conductivity } & Top & -0.0378 & & 6.73 & & $\mathrm{mS}$ \\
\hline & Bottom & -0.1231 & -0.0383 & 17.805 & 3.289 & $\%$ \\
\hline & Mid & -0.0375 & & 3.365 & & $\%$ \\
\hline Salinity & Top & -0.0422 & & 4.095 & & $\%$ \\
\hline
\end{tabular}


The surface area at the bottom of the reactor is a critical parameter in the mineralization process. It may not be apparent that a simple ratio between TDS that prevailed in UASB experimental reactor on the $47^{\text {th }}$ day and average concentration of the predicted values were adequate to determine the desired diameter $\mathrm{D}$ in up-scaling. If we consider that the lowest concentration is taken for up-scaling, D will be very small and vis versa if the highest saturation concentration is considered. In the event, if the highest saturation concentration would come upon, very high mineralization rate of the first phase could counter act in reducing the high concentration. The reasoning behind choosing the average and the lowest could be deduced from the equation (7), when TDS approaches $T D S_{t=14.5}$, at the mean, the value of $\alpha_{a} \times 75.6 \mathrm{~g} / \mathrm{L}$ tends towards 1 , thus $D=0.15 \mathrm{~m}$, being the experimental diameter $d$. It can be seen in eq. (7) that $d$ and $T D S_{t=47}$ and $\alpha_{a}$ are known values, thus eq. (7) could be simplified to eq. 10. The relationship is shown in Fig.3.

$$
D=\sqrt{0.001624 \times T S_{i}}
$$

It can be observed that towards end of experimentation, whenever feeding was done, the TDS, salinity and conductivity did not increase significantly as compared to other parameters. This may be due to greater amount of granular formations without being laden with ionic compounds towards the end of experimentation. When minerals are attached to the granules, it requires greater buoyancy effect to overcome gravitational forces, thus almost all of the research has been focused on increasing the surface area of the granules and creating more number of granules (Nicolella et al., 2000; McHugh et al., 2003; Pol et al., 2004; Zhou et al., 2007). As a consequence, the excess minerals are washed out from the outlet placed on the top of the reactor. Invariably, concentration of heavier ion compounds will settle at the sludge layer leading to inhibitive conditions or undesirable reactions causing inhibitions. It should be noted that all enzyme activities are dependent on $\mathrm{pH}$ and ionic strength (Jensen et al., 1972; Kendall et al., 1993; Bisswanger et al., 2014), thus equilibrium of the inorganic substances could be maintained to produce the desired enzymes along the length of the tall reactor, if the excess inorganic substances are precipitated and mineralized in the biofilter liner system. However, addition of substances such as iron, nickel, cobalt, selenium, and molybdenum can enhance methane gas generations (Weiland et al., 2010). Rapid gas generations in the sludge blanket due to hydrolysis and acidogenic reactions also promote vertical movement of the granules. This movement will facilitate if the mineral content is not excessive. The liner system promotes mineralization and it functions on the principle of natural attenuation at permeability rate of $1 \times 10^{-7} \mathrm{~cm} / \mathrm{s}$. This value is much lower than the permeability of the experimental liner. Therefore, it is imperative to increase the thickness of the liner and compact the composite liner system that can withstand the pressure due to the reactor height. The mare increase of diameter from $0.15 \mathrm{~m}$ to $0.35 \mathrm{~m}$ could increase the rate of mineralization by 5.44 times. 


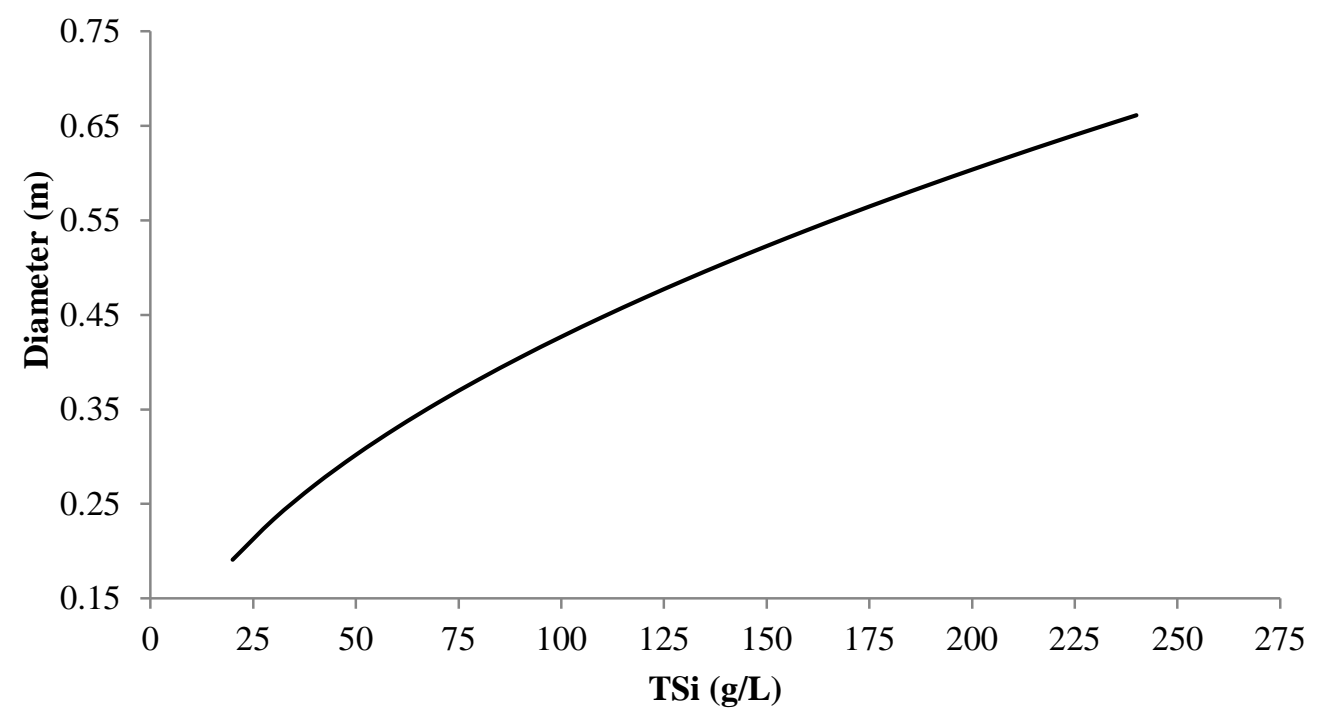

Figure 3. Predicted diameter based on TDS and $\mathrm{TS}_{\mathrm{i}}$

\section{Height}

The criteria used in determining the height of a UASBR could be governed by the scaled up TDS concentrations to that of the maximum experimental concentrations for each of the layers with respect to each of the volumes as given in eq. 9. The predicted height of a layer depends on the thickness of a particular concentration within a given strata that existed in the experimental unit. In the case of the bottom part of the reactor, it is the sludge layer that is being considered as the thickness. The cumulative TDS values of the bottom layer are shown in Figure 4. In comparison, the predicted values, using eq. (3a), (3b) and Table 1 are much higher because experimental data points are lacking for some of the days, particularly at the beginning. When we amalgamated experimental with the predicted values for the missing ones, the simulation of the adjusted experimental values can be plotted to give probable values as shown in Figure 4. It is important to visualize conceptually the difference between the quantity of TDS remaining and the quantity transformed to gases in the decomposition and mineralization processes in the experimental reactor. Eq. (4) can be used to describe the transformation of $T D S_{o}$ to these products $\left(T D S_{p}\right)$. Therefore, the cumulative values can be expressed as; $T D S_{p}=T D S_{o 1}\left(1-e^{-k_{1} t}\right) \quad$ (4a),

$T D S_{p}=T D S_{o 2}\left(1-e^{-k_{2}(t-22)}\right)$

$T D S_{p}$ will approach $\left(\left(T D S_{o 1}\right)_{t=22}+T D S_{02}\right)$ when $t \rightarrow \infty$. Therefore, $T D S_{o 1}$ and $T D S_{c 1}$ can be obtained for each of the layers and the results are given in Table 2. It should be noted that $T D S_{c 2}$ was taken into account in determining the height of bottom layer. There are two dependent variables in eq. (9), in which scaled-up height $\mathrm{H}$ remain the same as long as the loading rate (LR) exceeds on a daily basis the laboratory experimental value. $T D S_{c 1 \& c 2}$, $T D S_{o 1}$ and the initial concentration of feeding $75.6 \mathrm{~g} / \mathrm{L}$ can be written as a constant $(L R F)$, where; $L R F_{B}=\frac{T D S_{c 1 \& c 2}}{T D S_{o 1} \times 75.6}=\frac{181}{15.4 \times 75.6}=0.156 . L R F_{B}$ is the loading rate factor for the 
bottom layer. Therefore, eq.(9) can be written for each of the layers or combined as; $H=\frac{L R F \times L R \times d^{2} \times h}{D^{2}}$

Where; $L R=$ loading rate on a daily basis.

\section{The design}

The design height of the reactor will always remain at $3.4 \mathrm{~m}$ for kitchen wastes immaterial of the loading rate because according to the design parameters, the surface area of the base increases with increase in input concentration. Therefore, the upward velocities would be within suitable ranges to enhance the stability of the sludge granules while increasing the efficiency of mineralization due to biofilter liner system. Further, the increased cross section of the reactor below the sedimentation compartment would be a strategy for better reactor performances. It is necessary to avoid the preferential pathways through the sludge bed as much as possible. Therefore, the feeding materials/ the substrate should be uniformly distributed in the lower part of the reactor to ensure a close contact between the granules and the substrate. The shape of the surface area of the reactor can be either circular or rectangular. The design of gas, solid and liquid separating device (three phase separator) depends on the characteristics of feeding materials, type of sludge present in the reactor, the organic load applied, the expected bio gas production and dimensions of the reactor. The surface area of the apertures between the gas collectors should be 15-20\% of the reactor surface area (Lettinga and Pol, 1991). The overlap of the gas deflectors in relation to the opening for the settler compartment should be $0.1 \mathrm{~m}$ to $0.15 \mathrm{~m}$ and the depth of the settler compartment is about 0.3 of the total height of the reactor (Lettinga and Pol, 1991). The minimum slope of the settler walls is $45^{\circ}$ and optimum slope of the settler walls is $50-60^{\circ}$ (Chernicharo, 2007). To fabricate the three phase separator, non-corrosive and less bulky materials such as $P V C$, fiberglass and corrosive resistant stainless steel can be used. Concrete and steel have been the materials most commonly used for constructing UASB reactors usually with internal coating protection (Chernicharo, 2007). High quality concrete should be used and casting should be executed much care such as an extra cover or $P V C$ lining. Interventions of the experimental reactor for the start-up can be practiced to facilitate the startup of the scaled up reactor. For that, samples from the bottom, middle and top strata of the reactor can be obtained daily for monitoring $\mathrm{pH}$, conductivity, salinity, and TDS. A satisfactory operation of the UASBR requires proper control of the system and, as far as possible and economical, the maintenance of optimal environmental conditions (Lettinga and Pol, 1991). 


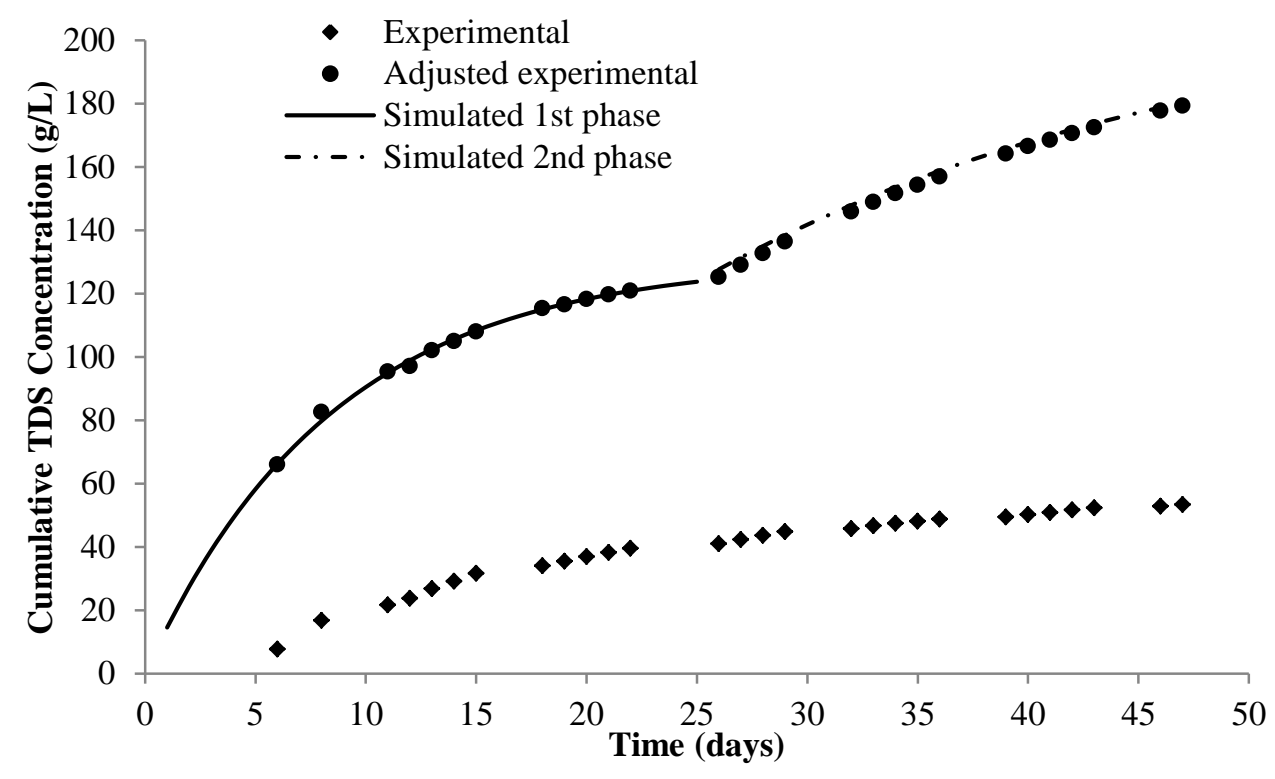

Figure 4. Cumulative TDS concentration variations with time

Table 2. Scaled-up dimensions of the UASBR

\begin{tabular}{lccrrr}
\hline Layer & $\begin{array}{c}\text { Concentration } \\
(\mathbf{g} / \mathbf{L})\end{array}$ & $\begin{array}{c}\text { Fraction } \\
\text { (Conc.) }\end{array}$ & $\begin{array}{c}\text { Thickness h } \\
(\mathbf{m})\end{array}$ & $\begin{array}{c}\text { Scaled-up } \\
\text { Height H } \\
(\mathbf{m})\end{array}$ & $\mathbf{R}$ \\
\hline Bottom & 2.75 & 0.47 & 0.51 & 1.11 & 0.32 \\
Mid & 1.54 & 0.26 & 0.29 & 1.15 & 0.33 \\
Top & 1.62 & 0.27 & 0.30 & 1.17 & 0.34 \\
Total & 5.91 & 1.00 & 1.10 & 3.43 & 1.00 \\
\hline Note: D $=0.35$ m and loading rate of 75.6 g/L/day (4.2 kg/day) & & & \\
$R=$ Ratio of predicted layer thickness to total scaled up height & & & & \\
\end{tabular}

\section{CONCLUSIONS}

The data and information derived from the experimental reactor were adequate to develop a mathematical model for designing scaled-up versions to treat kitchen wastes. The model was based on first order rate reactions of TDS to determine reactor dimensions of both the diameters and the height for desired loading rates. The height of the reactor would always remain the same since the surface area of the base should be increased to accommodate increased loading rates. Increasing the surface area is the critical design parameter to ensure mineralization of excess ions. 


\section{ACKNOWLEDGEMENTS}

This investigation received financial support from National Science Foundation of Sri Lanka under Grant No. NSF/SCH/2017/09.

\section{REFERENCES}

Annachhatre, A.P. (1996). Anaerobic treatment of industrial wastewaters. Resour. Conserv. Recy. 16 (1-4), 161-166.

Awe, O.W., Lu, J., Wu, S., Zhao, Y., Nzihou, A., Lyczko, N. and Minh, D.P. (2017). Effect of oil content on biogas production and performance stability of anaerobic digestion of food waste. In: Proceedings of $5^{\text {th }}$ International Conference on Sustainable Solid Waste Management, Athens, 21-24 June 2017.

Mata-Alvarez, J. (2003). Biomethanization of the organic fraction of municipal solid wastes. Iteso Welfare Association, United Kingdom.

Bisswanger, H. (2014). Review: Enzyme assays. Perspect. Sci. 1(1-6), 41-55.

Bouallagui, H., Touhami, Y., Cheikh, R.B. and Hamdi, M. (2005). Bioreactor performance in anaerobic digestion of fruit and vegetable wastes. Process Biochem.40, 989-99.

Chen, Z., Ren, N., Wang, A., Zhang, Z. and Shi, Y. (2008). A novel application of TPADMBR system to the pilot treatment of chemical synthesis-based pharmaceutical wastewater. Water Res. 42, 3385-3392.

Chen, Z., Wang, H., Chen, Z., Ren, N., Wang, A., Shi, Y. and Li, X. (2011). Performance and model of a full-scale up-flow anaerobic sludge blanket (UASB) to treat the pharmaceutical wastewater containing 6-APA and amoxicillin. J. Hazard. Mater. 185, 905913.

Chernicharo, C.D.L. (2007). Anaerobic reactors: Biological waste treatment series. IWA Publishing, London, UK.

Dung, T.N.B., Sen, B., Chen, C., Kumar, G. and Lin, C. (2014). Food waste to bioenergy via anaerobic processes. Energy Procedia, 61, 307-312.

Gunarathna, H.A.Y.R., Karunarathne, S.A., Basnayake, B.F.A., Galagedara, L.W. and Sangeetha, T. (2010). Evaluation of reactivity and inhibitions in developing municipal solid waste landfill bioreactors for tropical climatic conditions. Trop. Agric. Res. 21(4), 378-390. 
Habeeb, S.A., Latiff, A.B.A.B.A., Daud, Z.B. and Ahmad, Z.B. (2011). A review on granules initiation and development inside UASB Reactor and the main factors affecting granules formation process. Int. J. Energy Environ. 2(2), 311-320.

Jha, A.K., Li, J., Zhang, L., Ban, Q. and Jin, Y. (2013). Comparison between wet and dry anaerobic digestions of cow dung under mesophilic and thermophilic conditions. Advances in Water Resource and Protection, 1 (2), 28-38.

Jensen, H.B. and Kleppe, K. (1972). Effect of ionic strength, pH, amines and divalent cations on the lytic activity of t4 lysozyme. Eur. J. Biochem. 28, 116-122.

Karunarathna, R.H.M., Ariyawansha, R.T.K. and Basnayake, B.F.A. (2017). Start-up of an up-flow Anaerobic Sludge Blanket Reactor Built-in with a Bottom Liner of for Food Waste. In: Proceedings of $4^{\text {th }} 3 R$ International Scientific Conference on Material Cycles and Waste Management New Delhi, India, 8-10 March, 2017.

Kendall, T.L., Koohmaraie, M., Arbona J.R., Williams, S.E. and Young, L.L. (1993). Effect of $\mathrm{pH}$ and ionic strength on Bovine m-calpain and calpastatin activity. J. Anim. Sci. 71, 96104.

Lettinga, O. and Pol, L.W.H. (1991). UASB-process design for various types of wastewaters. Waf. Sci. Tech. 24 (8), 87-107.

Mata-Alvarez, J., Cecchi, F., Llabrés, P. and Pavan, P. (1992). Anaerobic digestion of the Barcelona central food market organic wastes: plant design and feasibility study. Bioresour. Technol. 42, 33-42.

Mahmoud, N., Zeeman, G., Gijzen, H. and Lettinga, G. (2004). Anaerobic sewage treatment in a one-stage UASB reactor and a combined UASB-Digester system. Water Res. 38, 2348 2358.

McHugh, S., O’Reilly, C., Mahony, T., Colleran, E. and O'Flaherty, V. (2003). Anaerobic granular sludge bioreactor technology. Rev. Environ. Sci. Biotechnol. 2, 225-245.

Melidis, P., Georgiou, D. and Aivasidis, A. (2003). Scale-up and design optimization of anaerobic immobilized cell reactors for wastewater treatment. Chem. Eng. Process. 42, 897908.

Misi, S.N. and Forster, C.F. (2002). Semi-continuous anaerobic co-digestion of agro-waste. Environ. Technol. 23, 445-451.

Nagao, N., Tajima, N., Kawai M., Niwa, C., Kurosawa, N., Matsuyama, T., Yusoff, F. Md. and Toda, T. (2012). Maximum organic loading rate for the single-stage wet anaerobic digestion of food waste. Bioresour. Technol. 118, 210-218. 
Nicolella, C., Van Loosdrecht, M.C.M. and Heijnen, J.J. (2000). Wastewater treatment with particulate biofilm reactors. J. Biotechnol. 80(1), 1-33.

Oktem, Y.A., Ince, O., Sallis, P., Donnelly, T. and Ince, B.K. (2008). Anaerobic treatment of a chemical synthesis-based pharmaceutical wastewater in a hybrid upflow anaerobic sludge blanket reactor, Bioresour. Technol. 99, 1089-1096.

Pol, H. L.W., Lopes, S.I.C., Lettinga, G. and Lens, P.N.L. (2004). Anaerobic sludge granulation. Water Res. 38, 1376-1389.

Sweere, A.P.J., Luyben K.Ch. A.M. and Kossen, N.W.F. (1987). Review: Regime analysis and scale down: toots to investigate the performance of bioreactors. Enzyme Microb. Technol. 9, 386-398.

Thaveesri, J., Daffonchio, D., Liessens B., Vandermeren, P. and Verstraete, W. (1995). Granulation and sludge bed stability in upflow anaerobic sludge bed reactors in relation to surface thermodynamics. Appl. Environ. Microbiol. 16(10), 3681-3686.

Thivyatharsan, R., Gunarathna, H.A.Y.R, Basnayake, B.F.A. and Kuruparan, P. (2012). Performance and suitability of a landfill bioreactor with low cost biofilm contained claywaste polyethylene-clay composite liner system for tropical climates of Asian countries. J. Mater. Cycles Waste. 14(1), 27-37.

Weiland, P. (2010). Biogas production: current state and perspectives. Appl. Microbiol. Biotechnol. 85, 849-860.

Wen, Z., Wang, Y. and Clercq, D.D. (2016). What is the true value of food waste? A case study of technology integration in urban food waste treatment in Suzhou City. China. J. Clean. Prod. 118, 88-96.

Zhou, W., Imai, T., Ukita, M., Li, F. and Yu, A. (2007). Effect of loading rate on the granulation process and granular activity in a bench scale UASB reactor. Bioresour. Technol. 98, 1386-1392. 